\title{
FIRE TESTS ON POLYESTER POLYMER MORTARS
}

\author{
Carmen Galán Marin, Manuel Olivares Santiago, \\ Jorge Roa Fernändez, Reyes Rodríguez Garcia \\ Escuela Técnica Superior de Arquitectura de Sevilla, Spain \\ Departamento de Construcciones Arquitectónicas I. \\ e-mail: cgalan(a)us.es \\ João Rodrigues \\ Instituto de Engenharia Mecánica e Gestão Industrial (INEGI). \\ Porto, Portugal
}

\begin{abstract}
Composite materials made from organic matrices are generally combustible. It is necessary to determine in each case their behaviour under fire and determine whether they fulfil the requirements of the applicable standards in order to match each material to each specific application.

Polyester polymer mortar is a material that provides much better mechanical characteristics than traditional mortars but one of its weak points is fire reaction. In this paper, fire reaction of a particular polyester polymer mortar is determined based on Spanish standards, in order to establish its suitability as a coating and cladding material for building construction.
\end{abstract}

Keywords: polymer mortar, polyester resin, fire reaction, radiation test

\section{INTRODUCTION}

\subsection{Fire reaction}

Fire reaction is one of the properties that mostly restrict the use of polymer mortars (PMs) in construction. (Browne et al., 1975). Both polyester and epoxy resins are highly flammable and combustible, but mortars prepared with them do not burn so easily due to their high aggregate percentage.

Therefore, it is very important to determine the behaviour of a polymer mortar against fire to ensure its applicability as a building material both from the point of view of structural security as well as the security of the occupants of the building. 
PMs contain an easily flammable and combustible component, the resin. They usually produce a great quantity of smoke and hazardous gases when burning.

One of the first groups of researchers to deal with this problem (Suzuki et al., 1975) carried out tests according to JIS (Japanese Industrial Standards).

After the very first tests, the material disintegrated and hence they recommend the use of a fire retardant agent to inhibit combustion. For the use of PMs in structural elements a fire-protection coating is proposed.

Further tests were made using Dawsonite (pirolysis-modified mineral, $\left.\mathrm{NaAl}(\mathrm{OH})_{2} \mathrm{CO}_{3}\right)$ as fire retardant agent. According to the manufacturer's specifications its addition also reduces the heat generation. The ignitioninhibition effect of the use of antimonium trioxide $\left(\mathrm{Sb}_{2} \mathrm{O}_{3}\right)$ in the mixture was also evaluated. But the paper concludes that the retardant effect is limited up to $550^{\circ} \mathrm{C}$, which is not considered high enough in case of fire and raise the need for evaluation of more effective fire delayers. However, other authors (Troitzsch et al. 1990) established that $\mathrm{Sb}_{2} \mathrm{O}_{3}$, the main antimony compound used commercially, shows no perceptible flame-retardant action on its own.

According to some authors (Browne et al. 1975) PMs are usually classified Class 1 or Class 2 (British Standard BS. 476, part 7) for surface spread of flame. They have concluded that a long exposure to high temperatures causes a degradation of the material and loss of strength. Safe working limits are about $60^{\circ} \mathrm{C}$ for continuous exposure. Temperatures about $100-120^{\circ} \mathrm{C}$ could be acceptable for brief periods, for example during steam cleaning.

\subsection{Fire Test Standards}

It is very difficult to determine the exact equivalences between different test results due to the great number of different standards and test procedures, which differ from one country to another.

More recently some researchers (Troitzsch et al. 1990) have tried to make a compilation of all the standards and procedures in order to simplify this task. In fact, we have just received a new European classification specifically concerning the reaction to fire of construction materials: the Euroclasses (Escriche, 2002) that will be in use in 2004.

The European directive for building materials classifies them from $\mathrm{A}$ to $\mathrm{F}$ according to their behaviour under the fire tests included in that directive. 
Single Burning Item (SBI, EN 13823) is the test used to classify building materials (except form flooring materials) into A2, B, C and D classes. In this test the combustion is supported by a propane burner. The amount of heat and smoke provoked are measured while particle projection and flaming droplets are just observed.

When the present research was under development, European Standards for fire reaction were still in the final harmonization phase. The "second generation" group of tests - based either on radiant panels or in the epirradiator - use specimens with a surface bigger than $1000 \mathrm{~cm}^{2}$. Ignition times, flame propagation and the variation of the thermal balance are the parameters controlled in these types of tests. There are three different streams for these Standards: French, British and German ones. The French stream includes Portuguese, Spanish, Belgian and Spanish Standards, and they have no requirement for smoke or toxicity of gases produced by combustion of building materials.

All the tests included in this paper were carried out according to Spanish Standards. It is noteworthy that, since there is no correlation between the classifications determined through Euroclasses and those obtained following national standards (Smith et al. 1999), the results of these tests are not comparable with similar results according to different standards.

\subsection{Characteristics of the polymer mortar}

The polymer mortar under study is made of a type of limestone aggregate very commonly found in the province of Seville. Its chemical composition analysis is shown in Table 1. This aggregate is commonly used as raw material for the local cement industry due to its high content of lime.

Table 1

Crushed or sifted aggregate chemical composition.

\begin{tabular}{|c|c|}
\hline Components & \% in weight \\
\hline $\mathrm{SiO}_{2}$ & $12,6-13,6$ \\
\hline $\mathrm{Al}_{2} \mathrm{O}_{3}$ & $0,8-1,0$ \\
\hline $\mathrm{Fe}_{2} \mathrm{O}_{3}$ & $1,7-2,3$ \\
\hline $\mathrm{CaO}$ & $45,4-47,0$ \\
\hline $\mathrm{MgO}$ & $0,4-0,6$ \\
\hline
\end{tabular}


The mortar produced with this aggregate has a nice natural colour and appealing appearance. The main objective of the current research is to develop a polymer mortar with this local aggregate for producing coating and cladding elements such as slabs or panels of various dimensions to be used for different applications in the local building industry.

The granulation used ranges in between the rates recommended by ASTM-33 and ACI, well known for producing conventional high-compact cement mortars with a minimum quantity of conglomerate.

Sizes are limited to $5 \mathrm{~mm}$. maximum and $0.16 \mathrm{~mm}$. minimum size.

The resin used for the polymer mortar was an unsaturated polyester (UP) resin. This type of resin is often used in the building industry by experts and researchers, due to its very good price/quality rate.

Two different resins were used for the tests: an orthophthalic and an isophthalic polyester resin. The resins (by Rhone(B) were ESTRATIL® AL100 (orthophthalic polyester) and ESTRATIL® 66-03 (isophthalic polyester). Both composed UP resins, were dissolved in styrene (30-33\% styrene). They were pre-accelerated to decrease the hardening time.

The polymerisation process, also named set or hardening process, was activated with the catalyst named MEK.PEROXIDE It was a $33 \%$ solution of methyl ethyl ketone peroxide in dimethyl phthalate. This catalyst was added in weight proportion between 3 and $5 \%$ to the liquid polyester unsaturated resin.

The catalyst activates the resin that starts the polymerisation process at room temperature. The resin is mixed with the catalyst and immediately afterwards aggregates are added. This mixture gives rise, after a polymerisation process under room temperature, to the polymer mortar.

The influence of the moisture degree of the aggregate used in a polymer mortar can be very important for the mechanical strength. We intended to detect whether it has some influence or not on other properties of the material such as its behaviour against fire.

Drying the aggregates always involves increasing the cost of the final product. Hence, the definition of the real influence of moisture in the final properties of the polymer mortar was considered important for the objectives of this research. Comparative studies between the results of tests done for polymer mortars prepared with $5 \%$ moisture in the aggregate and prepared with dried aggregate have been conducted. 
According to this, four different mixes were prepared, as the result of combining two types of resin (orthophthalic and isophthalic polyester) and dried or wet aggregates. We have marked the mixes in the following manner:

- OW: orthophthalic resin and wet aggregates

- OD: orthophthalic resin and dry aggregates

- IW: isophthalic resin and wet aggregates

- ID: isophthalic resin and dry aggregates

The proportion used was always $20 \%$ of mixture (resin+ catalyst) and $80 \%$ of aggregate. This means a basic proportion 1:4.

\section{TEST DEVELOPMENT}

\subsection{Test standards}

To determine the fire reaction requirements of a building construction material according to Spanish Standards it is necessary to determine the class they must meet. These classes are named M0, M1, M2, M3 and M4 in UNE 23727-90 Standard. This classification is also included in the NBE-CPI/96 (Fire Protection Conditions). The fulfilment of this norm is legally required for any building erected in Spain.

The classification indicates how much the different materials can contribute to the development of fire. According to this NBE-CPI/96 (Article 13.2), M0 class indicates that a material is not combustible under the thermal conditions of the corresponding standard test. A Ml material is combustible but not flammable. This is to say that the combustion ceases when the external heating source is interrupted. Materials M2, M3 an M4 are respectively moderately, medium or highly flammable.

M0 materials are always completely inorganic materials or with a very small percentage of some organic compound of low combustible characteristic such as phenol resins. $\mathrm{Ml}$ is the best classification possible for organic materials but only possible to obtain (Alonso et al. 1996) employing special organic matrices such as phenol, melamine-formaldehyde or ureaformaldehyde resins and with given levels of inorganic loads. Rigid PVC for example could obtain a M2 class.

Composites made of thermosetting resins such as unsaturated polyester, epoxy, vinyl-ester, polyurethane, etc. belong to M4 class, or cannott be classified because they do not fulfil minimum requirements for M4 class, giving an idea of their fire reaction. 
Tests according to UNE 23-721-90 (Fire reaction tests for building materials. Radiation test applicable to rigid materials -coating materials- of any thickness and flexible material over $5 \mathrm{~mm}$ thick) have been carried out to determine the fire reaction of the polymer mortars specified before. UNE Standard 23-727-90 (Fire reaction tests for building materials. Classification for building materials) was used to classify the material.

According to these Standards, materials are tested depending on the intended use, method of application and taking into account physical and geometrical characteristics, composition, colour, etc. Tests can only be carried out on slab like specimens.

The specimens were subjected to a constant radiation heat in a controlled chamber, eventually promoting the ignition of the escaped gases and the propagation of the combustion. Ignition times, flame longitude and the variation of the thermal balance are measured inside the test chamber.

The tests have been carried out in the Laboratório de Ensaios de Reacção ao Fogo in the facilities of the Instituto de Engenharia Mecánica e Gestão Industrial INEGI) in Porto (Portugal), in cooperation between this institution and the University of Seville.

\subsection{Test equipment}

The test equipment includes:

- A chamber for tests (named epirradiator, Figure 2), provided with a chimney for smoke evacuation and also an extractor fan.

- A radiation heating source of $500 \mathrm{~W}$ whose radiant surface was a transparent quartz disk of $100 \mathrm{~mm}$ diameter.

- A specimens frame holder, placed at a $45^{\circ}$ angle above to the horizontal, at a distance of $250 \mathrm{~mm}$ of the bottom from the test chamber. The radiant disk is placed parallel to the frame at $30 \mathrm{~mm}$ of its upper surface. A steel grate is placed in the frame.

- Two burners: one in the lower part, and one in the upper. They must be movable, sliding, able to be controlled from outside. The fuel has to be gas, either butane or propane. During the test the burners can rather be in contact with the specimen or separated from it.

- A device to measure the difference of the temperature between incoming and outgoing gases.

According to UNE Standards four specimens of a specific size and shape (see Table 1) are required. Specimens of the four different PMs (OW, OD, 


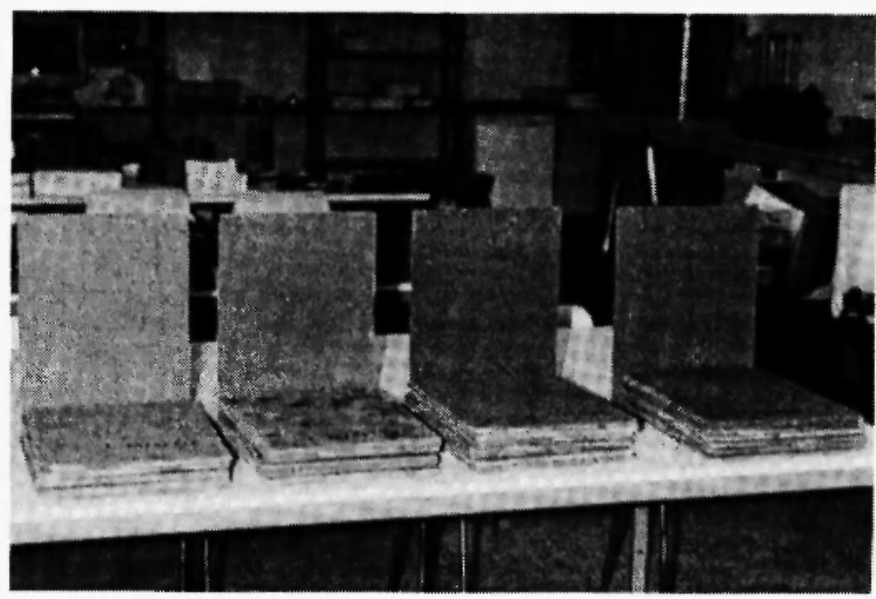

Fig. 1: Specimens prepared for radiation chamber

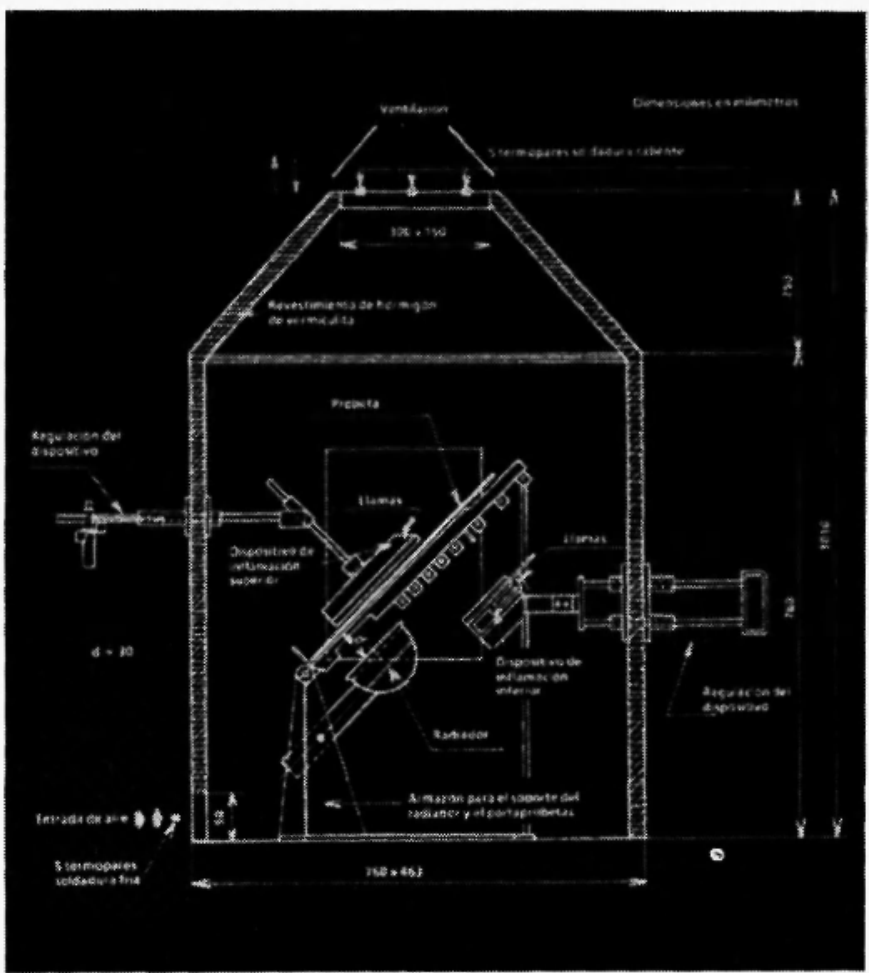

Fig. 2: Chamber for radiation tests according to UNE Standard: Epirradiator 
IW, ID) were tested. All specimens were flat plates of $400 \times 300 \times 10 \mathrm{~mm}$ size.

\subsection{Test procedure}

Specimens were conditioned at a temperature $23 \pm 2^{\circ} \mathrm{C}$ and humidity $50 \pm$ $5 \%$ during 368 hours, prior to testing. Then, the specimens were placed for 20 minutes inside the chamber which had been previously heated and thermally balanced.

The periods of time necessary to ignite the upper and the lower face of the specimen were recorded. The length of the flame, fusion or drops falling from the specimen (flaming or not) and the persistence of the combustion with or without flame after the end of the test were recorded.

The evolution of the fire (Figures 3 to 6) was followed through some different parameters that determine flammability, combustibility, flame propagation, dripping and heat loosening. This basically constitutes what is known as fire reaction of a material. The definition of this concept can be found in standards UNE 23026 as "the answer of a material to the fire that feeds and is exposed to".

According to the same standards, fire reaction is "the time in minutes that a construction element maintains its mechanical stability, flame tightness, thermal insulation and non-emission of flammable gases". Data provided during the test were used to calculate for each specimen the following rates, defined in UNE 23-721-90:

- i: flammability rate

- s: flame development rate

- $\mathrm{h}$ : maximum flame length rate

- c: combustibility rate

\section{TEST RESULTS}

\subsection{Radiation test results}

Results of the radiation tests are shown in Table 2. According to the parameters obtained in the tests in the radiation chamber, and taking into account that there were no flaming droplets, the class for reaction against fire was determined according to UNE 23-727-90 classification criteria (Table 2) for rigid materials,. 


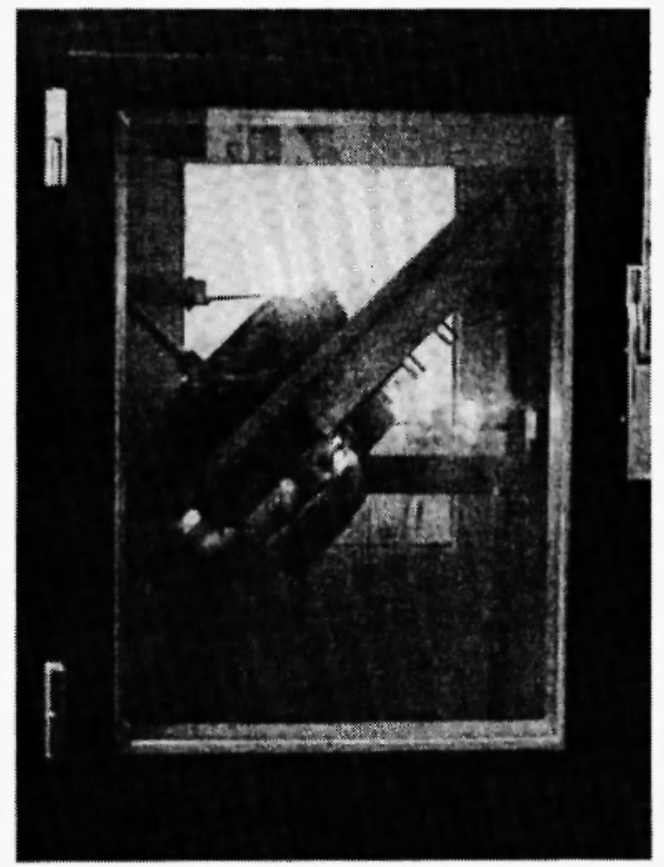

Fig. 3: Initiation of the test in the radiation chamber

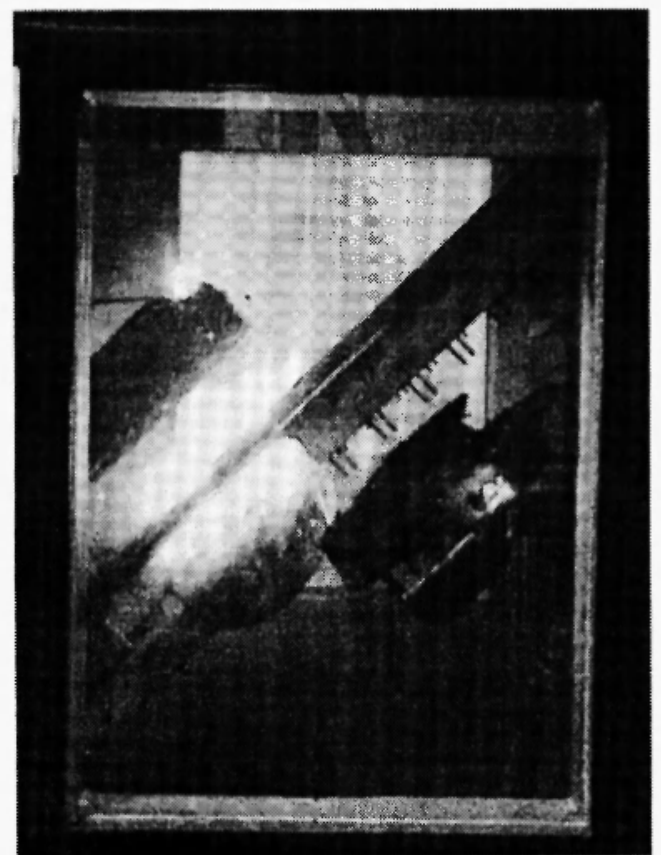

Fig. 4: Burning of the specimens 


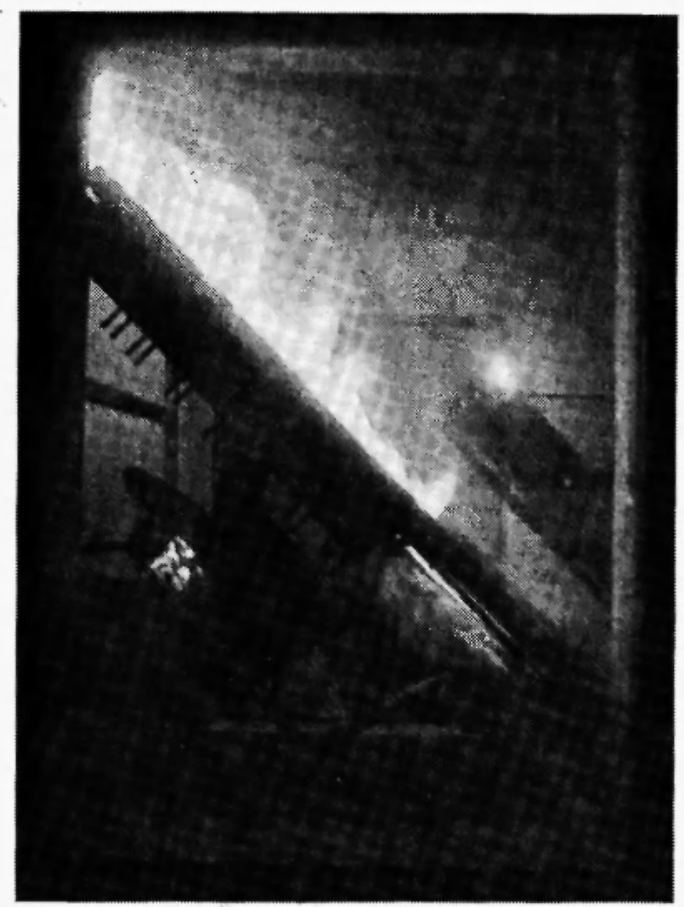

Fig. 5: Combustion of the specimen

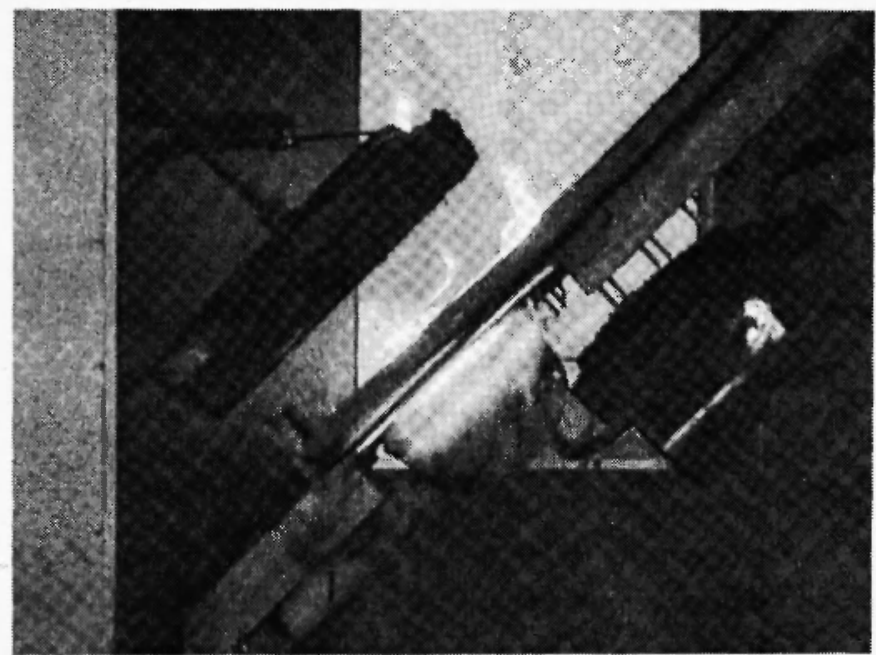

Fig. 6: End of the test 
Table 2

Specimens tested in a radiation chamber according to UNE 23-72 1-90

\begin{tabular}{|l|c|c|c|c|c|}
\hline $\begin{array}{l}\text { Specimen / } \\
\text { formulation }\end{array}$ & $\begin{array}{c}\text { Length } \\
(\mathbf{m m})\end{array}$ & $\begin{array}{c}\text { Width } \\
(\mathbf{m m})\end{array}$ & $\begin{array}{c}\text { Thickness } \\
(\mathbf{m m})\end{array}$ & $\begin{array}{c}\text { Weight } \\
(\mathbf{g})\end{array}$ & $\begin{array}{c}\text { Density } \\
\left(\mathbf{g} / \mathbf{c m}^{3}\right)\end{array}$ \\
\hline OW & & & & & \\
B 02-08 OW & 398 & 298 & 11.28 & 2395.0 & 1.79 \\
B 01-02 OW & 400 & 301 & 9.05 & 1857.3 & 1.70 \\
B 02-07 OW & 399 & 300 & 10.65 & 2213.6 & 1.74 \\
OD & & & & & \\
B 03-03 OD & 398 & 298 & 10.01 & 2440.7 & 2.06 \\
B 03-01 OD & 400 & 300 & 9.89 & 2200.4 & 1.85 \\
B 03-05 OD & 398 & 299 & 10.75 & 2480.2 & 1.94 \\
IW & & & & & \\
B 06-02 IW & 397 & 298 & 9.35 & 2297.1 & 2.08 \\
B 06-05 IW & 399 & 299 & 10.60 & 2471.3 & 1.95 \\
B 06-04 IW & 399 & 300 & 12.09 & 2876.0 & 1.99 \\
ID & & & & & \\
B 04-04 ID & 396 & 297 & 10.23 & 2306.5 & 1.92 \\
B 04-05 ID & 398 & 299 & 10.59 & 2245.5 & 1.78 \\
B 04-03 ID & 397 & 298 & 12.33 & 2695.4 & 1.85 \\
\hline
\end{tabular}

A very large quantity of black smoke was produced during the tests. Specimens of OW formulation disintegrated after 13 minutes of the test. IW specimens disintegrated at about 14 minutes. OD specimens disintegrated at 18 minutes and ID after 19 minutes. According to the results above (see Figure 7), we must conclude that these polymer mortars must be included in the M4 class for reaction against fire. M4 means the material is highly flammable.

\subsection{Discussion of the results}

Composite materials made from organic matrices are generally combustible. It is necessary to determine in each case their fire behaviour and to determine whether they fulfil the requirements of the applicable standards and for the specific application. 


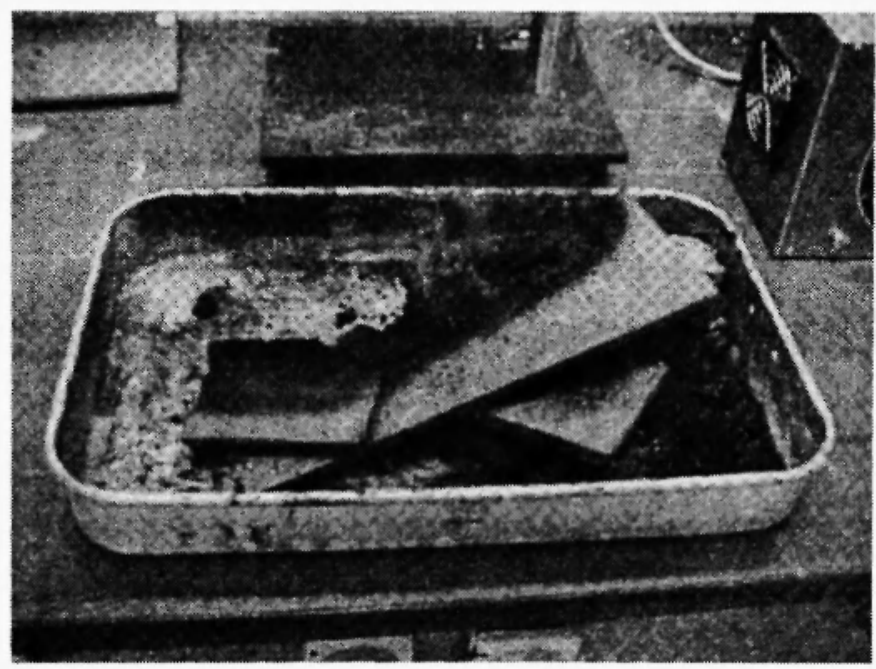

Fig. 7: The specimen after the test

Nevertheless research in new materials has made it possible to develop composite materials from organic matrix and a good fire reaction based on the fireproofing of traditional resins or on the development of new fireproof matrices. Therefore it is possible to raise the classification of a material from M4 to MI without too much effect on other properties (Alonso et al. 1996).

According to Standard NBE-CPI 96, (Article 16.1) materials suitable for cladding or surface coating in corridors, staircases and areas included in fire evacuation paths must be class M2 (walls and ceilings) or M3 (floors) in general except in hospitals that have higher requirements. But the same standard specifies that no restrictions are given for linear elements such as corner brackets, joint caps, strips, banisters, skirting boards, also not for special elements like wall lamps, signs, tags, etc. For cladding materials in other areas of a building it is only specified (Article 16.3) that in residential buildings (applicable to hotels, hostels, pensions, etc., not to private housing) a minimum classification of $\mathrm{M} 3$ is required for surface coating or tiles on floors and M2 on walls and ceilings.

According to the previous explanation, if we intend to use this new material in the previously cited restricted areas (fire evacuation paths, or even more demanding e.g. hospitals, public buildings, etc) the standards constraints are clear. But for the rest the polymer mortar could be used with its actual conditions, as there are not higher requirements for coating 
materials. Nonetheless it does not seem to be advisable to use this new material without improving its reaction to fire.

For this kind of material there are several ways of fireproofing, so they must be studied and new research on this specific matter must be carried out. New appropriate tests must be done in order to check the new results for each of them. Different ways of making a material fire-resistant can be found, classified depending on the application way such as:

- Coating fireproofing: This is the application of a chemical substance named a "fireproofing" agent on the outer surface of the material. This substance reacts in a fire event or sparkles, or under a heat load, improves the behaviour of the material against fire. This method of fireproofing is widely used with textile materials such as curtains, carpets, etc. It is effective but has the disadvantage of not being permanent because, due to rubbing action, sweeping, hoovering, washing, or other different treatments, eventually disappearance of the coating starts and with it the fireproofing effect.

- In mass or composition fireproofing: This is the addition of some chemical substance to the mix during the manufacturing of the material. Composition fireproofing - also called reactive fireproofing - is based on the introduction of molecules into the polymer chain of the raw materials used to produce the polymer composite. The effects promoted by the fireproofing agent can be physical or chemical changes. The results that can be obtained vary from inhibition to suppression of the combustion process against the outer agents that may produce it. This kind of fireproofing is very effective and also permanent because it is inherent to the material. This is the most widely used kind of fireproofing treatment for organic matrix composites. Most commonly, substances of hydrated inorganic compounds (physical action) and halogen phosphor and nitrogen by-products (chemical action) are used.

- Another possibility to develop is to use resins with improved fire behaviour. In the market we can find M2 or even M1 resins. This classification could be improved by adding aggregates to the resin. Some examples of these resins available are UP fire retardant resins F 207 TPE, F 240 TF, F 820, and O F 804 TF from NESTE Chemicals. Prices and characteristics are similar to the orthophthalic and isophthalic resins we used in the tests. 


\section{CONCLUSIONS}

Based on the results of the tests shown in Table 3, the four different materials (OW, OD, IW and ID), unsaturated polyester mortars, can be classified as M4.

For all four materials, flammability rate (i), flame development rate (s), maximum flame length rate $(\mathrm{h})$ and combustibility rate (c), present similar values. Therefore it is possible to conclude that the use of orthophthalic or isophthalic resin and wet or dry aggregates does not affect the fire resistance of the PM.

Table 3

Results of the specimens tested in the radiation chamber according to UNE 23-721-90

\begin{tabular}{|l|c|c|c|c|}
\hline Specimen & i rate & s rate & h rate & c rate \\
\hline OW & & & & \\
B 02-08 OW & 0.65 & 8.08 & 2.05 & 8.30 \\
B 01-02 OW & 0.84 & 5.87 & 2.05 & 7.48 \\
B 02-07 OW & 0.66 & 7.21 & 2.05 & 8.60 \\
Average value & 0.72 & 7.05 & 2.05 & 8.13 \\
OD & & & & \\
B 03-03 OD & 0.56 & 6.52 & 1.80 & 10.15 \\
B 03-01 OD & 0.74 & 7.13 & 1.80 & 10.97 \\
B 03-05 OD & 0.69 & 7.94 & 2.05 & 8.15 \\
Average value & 0.66 & 7.20 & 1.88 & 9.76 \\
IW & & & & \\
B 06-02 IW & 0.54 & 7.64 & 2.05 & 6.42 \\
B 06-05 IW & 0.51 & 7.39 & 2.05 & 6.87 \\
B 06-04 IW & 0.52 & 7.35 & 2.05 & 6.39 \\
Average value & 0.52 & 7.46 & 2.05 & 6.56 \\
ID & & & & \\
B 04-04 ID & 0.57 & 7.52 & 1.80 & 7.42 \\
B 04-05 ID & 0.70 & 7.65 & 2.05 & 7.75 \\
B 04-03 ID & 0.50 & 7.41 & 2.05 & 5.23 \\
Average value & 0.57 & 7.53 & 1.97 & 6.80 \\
\hline
\end{tabular}


The application for prefabricated coating and cladding elements is possible. Nevertheless, to use the mortar in building construction (according to Spanish Standards) without restrictions it will be necessary to fireproof it.

Further research on this material is under development, focused on improving fire reaction characteristics. The use of either fireproof resins or composition fireproofing will improve fire behaviour of the material but some degradation on the mechanical properties is expected.

New tests will be carried out and will help to determine whether the polymer mortar is good enough just with additions in its composition (and which are the most suitable ones) or if it is desirable to introduce "fireproof" polyester resins.

\section{ACKNOWLEDGEMENTS}

The authors want to acknowledge Dr. Antonio Torres Marques, Dr. Antonio Ferreira and Eng. Cristina Ribeiro, researchers of the Instituto de Engenharia Mecánica e Gestão Industrial (INEGI) in Porto (Portugal) for the productive cooperation between both institutions. The authors also wish to acknowledge the two anonymous referees for their helpful suggestions that improved the earlier version of the paper. Radiation chamber tests have been carried out in the Laboratorio de Ensaios de Reacção ao Fogo of the INEGI, in Porto (Portugal).

\section{REFERENCES}

Alonso JR, Madariaga L, Vegara FJ (1996) "Reaccion al fuego de materiales compuestos de matriz orgánica", I Conferencia Internacional sobre los Materiales Compuestos aplicados en Arquitectura y Construccion, Seville, Spain, pp 73-82.

British Standards BS. 476, part 7, 1970.

Browne RD, Adams M, Frech EL (1975) "Experience in the use of polymer concrete in the building and construction industry", Proceedings of the 1 International Congress on Polymers in Concrete (ICPIC), The Construction Press, Lancaster, UK, pp 433-447.

Escriche FX (2002) "La nueva clasificación europea de reaccion al fuego de los materiales de construcción: las Euroclases". 16 Conference on Composite Materials. CEPMAC. Barcelona Spain. 
Galán Marín C (2001) "Caracterizacion de un mortero polimerico con resina de poliester insaturado y árido de albero para su aplicación en construccion". Unpublished PhD Thesis. University of Sevilla, Spain

NBE-CPI/96 (1996) "Normativa básica de la Edificacion: Condiciones de proteccion contra incendios en los edificios". (Spanish Standards for protection against fire in buildings).

NESTE Chemicals Products Information.

Suzuki H, Sugahara S (1975) "Fire Tests on models constructed of resin concrete", Proceedings of the I International Congress on Polymers in Concrete (ICPIC), The Construction Press, Lancaster, UK, pp 306-311.

Troitzsch J, Becker W, Bönold W (1990) "International Plastics Flammability Handbook", Hanser Publisher, Munich, Germany.

UNE $23721(1990,1990)$ "Ensayos de reaccion al fuego de los materiales de construccion. Ensayo por radiacion aplicable a los materiales rígidos o similares (materiales de revestimiento) de cualquier espesor y a los materiales flexibles de espesor superior a los $5 \mathrm{~mm}$ ". (Fire reaction tests for rigid or similar materials -coating materials, of any thickness and flexible materials over $5 \mathrm{~mm}$ thick).

UNE 23727 (1990) "Ensayos de reaccion al fuego de los materiales de construccion. Clasificación de los materiales utilizados en la construccion". (Fire reaction tests for construction materials. Classification of materials used in building construction).

Smith D, Shaw K (1999) "The Single Burning Item /SBI) Test. The Euroclasses and Transitional Arrangements". Proceedings of the INTERFLAM 99 Conference, Interscience Communications Limited, London, UK, pp 1-9. 